\title{
Developmental emergence of persistent memory for contextual and auditory fear in mice
}

\author{
Rojina Samifanni, ${ }^{1,3}$ Mudi Zhao, ${ }^{1,3}$ Arely Cruz-Sanchez, ${ }^{1,2}$ Agarsh Satheesh, ${ }^{1}$ \\ Unza Mumtaz, ${ }^{1}$ and Maithe Arruda-Carvalho ${ }^{1,2}$ \\ ${ }^{1}$ Department of Psychology, University of Toronto Scarborough, Toronto, Ontario M1C1A4, Canada; ${ }^{2}$ Department of Cell and Systems \\ Biology, University of Toronto, Toronto, Ontario M5S 3G5, Canada
}

\begin{abstract}
The ability to generate memories that persist throughout a lifetime (that is, memory persistence) emerges in early development across species. Although it has been shown that persistent fear memories emerge between late infancy and adolescence in mice, it is unclear exactly when this transition takes place, and whether two major fear conditioning tasks, contextual and auditory fear, share the same time line of developmental onset. Here, we compared the ontogeny of remote contextual and auditory fear in C57BL/6) mice across early life. Mice at postnatal day (P)15, 21, 25, 28, and 30 underwent either contextual or auditory fear training and were tested for fear retrieval 1 or $30 \mathrm{~d}$ later. We found that mice displayed 30-d memory for context- and tone-fear starting at P25. We did not find sex differences in the ontogeny of either type of fear memory. Furthermore, 30-d contextual fear retrieval led to an increase in the number of c-Fos positive cells in the prelimbic region of the prefrontal cortex only at an age in which the contextual fear memory was successfully retrieved. These data delineate a precise time line for the emergence of persistent contextual and auditory fear memories in mice and suggest that the prelimbic cortex is only recruited for remote memory recall upon the onset of memory persistence.
\end{abstract}

[Supplemental material is available for this article.]

Long-lasting memories, particularly of aversive events, are integral to guiding future behavior necessary for survival. The ability to form memories that persist across the life span, or memory persistence, emerges during early life across species (Campbell and Campbell 1962; Campbell and Spear 1972; Rubin and Schulkind 1997; Rubin 2000; Josselyn and Frankland 2012). Importantly, early life is also a time of heightened vulnerability to the effects of aversive experiences such as trauma and stress on long-term mental health outcomes (Heim and Nemeroff 2001; Syed and Nemeroff 2017; Schroeder et al. 2018). The accessibility and ease of genetic manipulation has made the mouse a popular and powerful model to study the etiology of mental and neurodevelopmental disorders. Still, very little is known about early life aversive memory processing in mice. While humans typically start displaying persistent episodic memories around the age of three (Waldfogel 1948; White and Pillemer 1979; Kihlstrom and Harackiewicz 1982; Howes et al. 1993; Rubin and Schulkind 1997; Rubin 2000; Squire 2004; Cleveland and Reese 2008; Davis et al. 2008; Tustin and Hayne 2010; Josselyn and Frankland 2012; Scarf et al. 2013), the onset of fear memory persistence in mice is less clear, taking place between postnatal day (P)17 and P30 (Akers et al. 2012; Guskjolen et al. 2018), corresponding to the interval between late infancy and adolescence (Spear 2000). Currently, it is unknown exactly when within this considerable timespan fear memory persistence emerges in mice, whether this onset differs across different memory types, or why it may be delayed compared with humans. Establishing the ontogeny of memory persistence in mice will provide an important tool for improving our understanding of the long-term consequences of harmful early life experiences, as well as improving the detection of early cognitive deficits in animal

${ }^{3}$ These authors contributed equally to this work.

Corresponding author: m.arrudacarvalho@utoronto.ca

Article is online at http://www.learnmem.org/cgi/doi/10.1101//m.053471.121 . models of neurodevelopmental disorders (Kaffman and Krystal 2012; Cope et al. 2016).

Substantial work has shown that memories acquired prior to the onset of memory persistence can be reinstated through behavioral and/or pharmacological manipulation (Campbell and Jaynes 1966; Haroutunian and Riccio 1977; Davis and Rovee-Collier 1983; Richardson et al. 1988; Kim et al. 2006; Callaghan et al. 2014; Spear and Parsons 2014; Travaglia et al. 2016b) and, more recently, optogenetic stimulation of neuronal ensembles in the hippocampus (Guskjolen et al. 2018). This recovery of forgotten infant memories suggests that remote memory retrieval, rather than memory storage, is affected when memories are encoded in early life. Still, not much is known about how memory encoding and retrieval mechanisms are altered during early development to shape memory persistence. Evidence points to hippocampal maturation as a major factor delineating the onset of memory persistence (Josselyn and Frankland 2012; Akers et al. 2014; Alberini and Travaglia 2017; Ramsaran et al. 2018; Travaglia et al. 2016a,b, 2018), consistent with the principle that maturation of underlying brain circuitry guides the timing of behavioral emergence. Importantly, as memory tasks differ in their brain circuit requirements, it is conceivable that the onset of memory persistence may vary even between cognate behavioral tasks. As our knowledge of the synaptic, cellular, and systems bases of remote memory formation continues to be challenged and updated (Albo and Gräff 2018), a significant body of research implicates brain regions such as the prefrontal cortex and amygdala in adult remote memory

(C) 2021 Samifanni et al. This article is distributed exclusively by Cold Spring Harbor Laboratory Press for the first 12 months after the full-issue publication date (see http://learnmem.cshlp.org/site/misc/terms.xhtml). After 12 months, it is available under a Creative Commons License (Attribution-NonCommercial 4.0 International), as described at http://creativecommons.org/licenses/by-nc/ $4.0 \%$. 
processing (Takehara et al. 2003; Frankland and Bontempi 2005; Vetere et al. 2011; Wheeler et al. 2013; Bergstrom 2016; Kitamura et al. 2017; Sathiyakumar et al. 2020). Nevertheless, the contribution of brain regions beyond the hippocampus to the remote recall of memories acquired in early life has not been examined.

Here, we explored these premises by establishing the ontogeny of memory persistence in C57BL/6J mice in two well-characterized Pavlovian fear conditioning protocols: contextual (Rudy and Morledge 1994; Anagnostaras et al. 2001; Maren 2001) and auditory (Brown et al. 1951; LeDoux et al. 1990; Phillips and LeDoux 1992; LeDoux 2000; Maren 2001) fear conditioning. We found that mice displayed a similar developmental emergence of persistent memory for both contextual and auditory fear, and further explored a role for the prefrontal cortex in the emergence of remote (30-d) contextual fear memory retrieval. Our findings establish a precise ontogenetic profile for different aspects of aversive processing in mice and offer the recruitment of the prefrontal cortex as a potential additional index for the emergence of persistent memory, further advancing our understanding of the neural correlates underlying persistent memory processing in early life.

\section{Results}

To investigate the onset of persistent memory for contextual fear, mice of different ages underwent contextual fear conditioning (120-sec baseline period followed by five shocks presented at 60 -sec intervals) and were tested following either a 1-d or 30-d delay period. Fear conditioning took place at one of five ages spanning late infancy to adolescence (Spear 2000): P15, P21, P25, P28, or P30 (Fig. 1A). One day after fear conditioning (1-d retrieval test), all age groups displayed robust freezing to the context, indicating mice in all age groups were able to retain the context-fear association for $24 \mathrm{~h}$ (one-way ANOVA, $F_{(4,70)}=2.14, P=$ 0.0852) (Fig. 1B). To assess at what age C57BL/6J mice are able to generate persistent memories for contextual fear, we trained and tested a separate cohort of animals $30 \mathrm{~d}$ after fear conditioning (30-d retrieval test). Both P15 and P21 mice showed minimal freezing $30 \mathrm{~d}$ after training, while P25, P28, and P30 mice displayed significantly higher freezing (one-way ANOVA, $F_{(4,57)}=12.10, P<$ 0.0001; Tukey's post-hoc test: P15 vs. P21: $P=0.9997$, P15 vs. P25: $P=0.0044$, P15 vs. P28: $P=0.0005$, P15 vs. $\mathrm{P} 30: P<0.0001$, P21 vs. P25: $P=0.0050, \mathrm{P} 21$ vs. P28: $P<0.0006$, P21 vs. P30: $P<$ 0.0001, P25 vs. P28: $P=0.9921$, P25 vs. P30: $P=0.6906$, P28 vs. P30: $P=0.8857$ ) (Fig. 1C). Importantly, late weaning at P25 did not rescue the deficits in persistent memory observed in animals

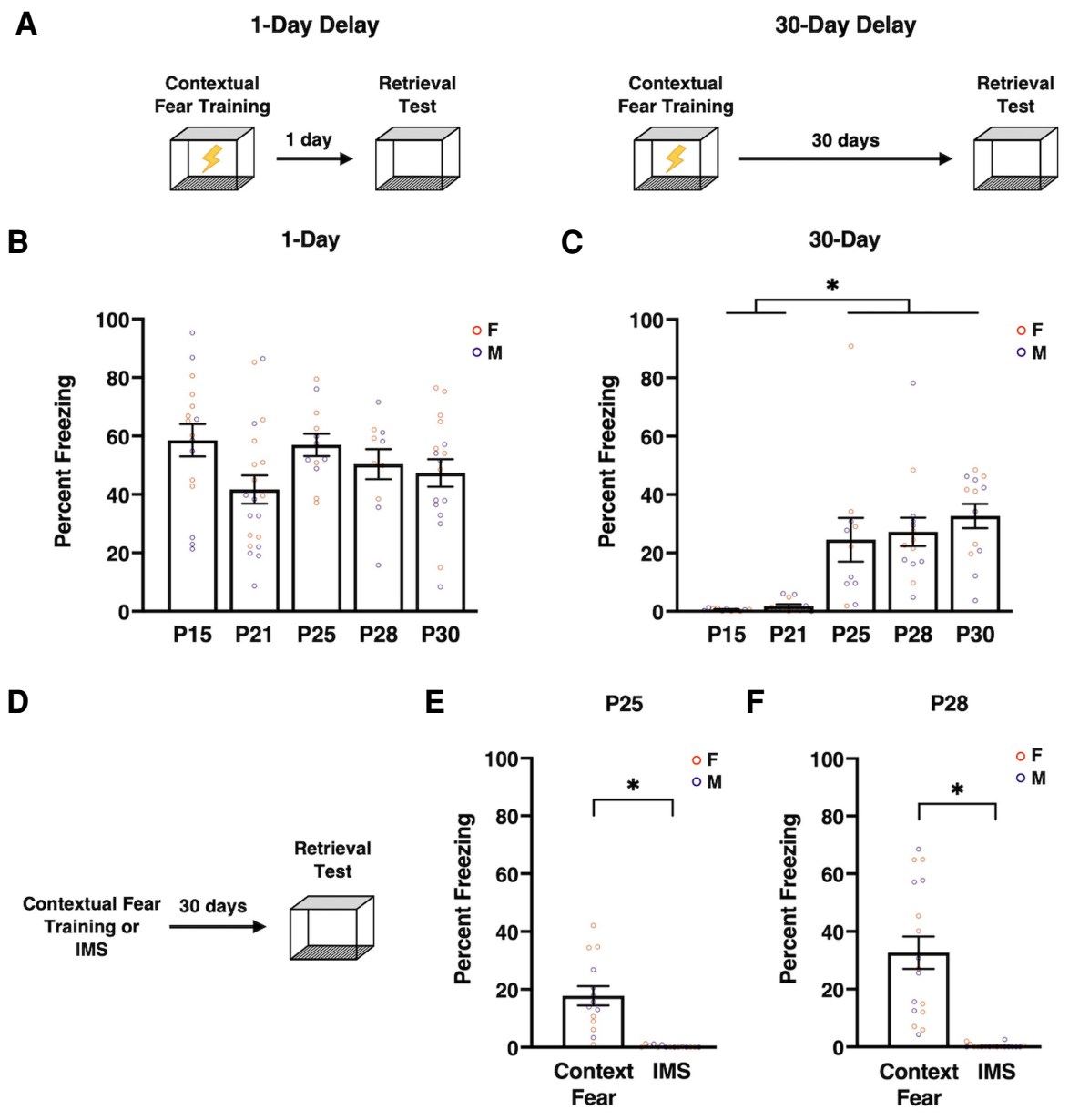

Figure 1. Ontogeny of persistent memory for contextual fear. $\mathrm{C} 57 \mathrm{BL} / 6 \mathrm{~J}$ mice were trained in contextual fear at either P15, P21, P25, P28, or P30, then tested for memory retrieval $1 \mathrm{~d}$ or $30 \mathrm{~d}$ later. Training consisted of a 120-sec acclimation period to the conditioning chamber, followed by five footshocks $0.5 \mathrm{~mA}, 2 \mathrm{sec}$ ) delivered at $60-\mathrm{sec}$ intervals. (A) Schematic of contextual fear conditioning. (B) Percent freezing to the context at the 1-d retrieval test. All age groups exhibited robust freezing behavior. P15, $n=16$ ( 8 males, 8 females); P21, $n=20$ (10 males, 10 females); P25, $n=12$ (6 males, 6 females); P28, $n=10$ (5 males, 5 females); P30, $n=17$ (9 males, 8 females). (C) Percent freezing to the context at the 30-d retrieval test. P15 and P21 mice displayed minimal freezing behavior, while P25, P28, and P30 mice showed significantly higher freezing. P15, $n=11$ (5 males, 6 females); P21, $n=13$ (7 males, 6 females); P25, $n=11$ ( 6 males, 5 females); P28, $n=14$ ( 8 males, 6 females); P30, $n=13$ (7 males, 6 females). (D) Schematic of contextual fear and immediate shock conditioning. group exhibited significantly higher freezing compared with the IMS group. Contextual fear, $n=14$ (7 males, 7 females); IMS, $n=15$ (8 males, 7 females). (F) Percent freezing at the 30 -d retrieval test in animals trained at P28. Animals in the contextual fear group exhibited significantly higher freezing compared with the IMS group. Contextual fear, $n=17$ (8 males, 9 females); IMS, $n=18$ (10 males, 8 females). All data represent mean \pm SEM. $\left({ }^{*}\right) P<0.05$. Female (orange) and male (purple) data points are identified, but no sex differences were found across experiments (see results for details). fear trained at P21 (average percent freezing $=1.85$, $\mathrm{SEM}=0.62$; male $n=9$, female $n=9$ ). These results suggest that the ability to generate persistent memories for contextual fear emerges between $\mathrm{P} 21$ and P25 in C57BL/6J mice.

To confirm that freezing at the 30 -d retrieval test is representative of the association between the context and shock, rather than a residual effect of footshock stress, a separate cohort of mice underwent either contextual fear or an immediate shock protocol (IMS) (Fig. 1D). The IMS protocol, whereby animals are shocked immediately upon being placed in the chamber, prevents the formation of a context-shock association while still exposing the animals to the footshock (Fanselow 1990; Frankland et al. 
2004b). Both P25 (unpaired t-test, $\left.t_{(27)}=5.42, P<0.0001\right)$ (Fig. $1 \mathrm{E}$ ) and P28 (unpaired $t$-test, $t_{(33)}=5.94, P<0.0001$ ) (Fig. $1 \mathrm{~F}$ ) mice in the contextual fear group showed significantly higher freezing compared with the IMS group at the 30-d retrieval test, suggesting that 30-d freezing in these age cohorts is driven by associative learning, rather than a residual consequence of stress (Fig. 1E,F). We found no significant effects of sex on 1-d (two-way ANOVA, main effect of age, $F_{(4,65)}=2.15, P=0.0847$, main effect of sex, $F_{(1,65)}=3.07, P=0.0846$, interaction effect of age $\times \operatorname{sex}, F_{(4,65)}=$ $0.55, P=0.7030$ ) (Fig. 1B) or 30-d memory retrieval for contextual fear (two-way ANOVA, main effect of age, $F_{(4,52)}=12.41, P<$ 0.0001 , main effect of sex, $F_{(1,52)}=1.56, P=0.2173$, interaction effect of age $\times$ sex, $F_{(4,52)}=1.14, P=0.3489$ ) (Fig. 1C).

Developmental emergence of behavior is related to the maturation of its underlying brain circuitry. Two commonly used fear conditioning protocols, contextual and auditory fear, differ in certain aspects of their circuit requirements (Phillips and LeDoux 1992; Maren 2001; Sotres-Bayon et al. 2012; Maren et al. 2013; Herry and Johansen 2014), which could affect their respective developmental emergence. To test whether there is a temporal dissociation in the onset of 30-d memory retrieval between contextual and auditory fear, we trained P15, P21, P25, and P30 animals in auditory fear and tested them either $1 \mathrm{~d}$ or $30 \mathrm{~d}$ later (Fig. 2A). One day after training, animals in all age groups displayed equivalent levels of freezing (one-way ANOVA, $F_{(3,33)}=0.61, P=0.6159$ ) (Fig. 2B). In contrast, P15 and P21 animals showed minimal freezing at the 30-d retrieval test, while P25 and P30 animals displayed significantly higher freezing (one-way ANOVA, $F_{(3,31)}=11.64, P<$ 0.0001; Tukey's post-hoc test: P15 vs. P21: $P=0.9757$, P15 vs. P25: $P=0.0272$, P15 vs. P30: $P=0.0004$, P21 vs. P25: $P=0.0230$, P21 vs. P30: $P=0.0001$, P25 vs. P30: $P=0.2398$ ) (Fig. 2 C), with in- creased freezing at tone presentation compared with baseline, suggesting a tone-shock association (Supplemental Fig. 1). Importantly, late weaning at P25 did not rescue the deficits in persistent memory for auditory fear observed in animals trained at P21 (average percent freezing $=3.84, \operatorname{SEM}=1.31$; male $n=7$, female $n=$ $8)$. These data suggest that the onset of 30-d auditory fear memory takes place between P21 and P25 in C57BL/6J mice, similar to the time line for contextual fear. We did not see a significant effect of sex in the 1-d retrieval (two-way ANOVA, main effect of age, $F_{(3,29)}=0.87, P=0.4700$, main effect of sex, $F_{(1,29)}=0.26$, $P=0.6120$, interaction effect of age $\left.\times \operatorname{sex}, F_{(3,29)}=0.34, P=0.7942\right)$ (Fig. 2B), but found a significant interaction between sex and age in the 30-d auditory fear retrieval test (two-way ANOVA, main effect of age $F_{(3,27)}=15.34, P<0.0001$, main effect of sex, $F_{(1,27)}=0.27, P=0.6107$, interaction effect of age $\times \operatorname{sex}, F_{(3,27)}=$ 5.34, $P=0.0051$; Sidak post-hoc test: P15 M vs. F: $P<0.9999$, P21 $\mathrm{M}$ vs. F: $P=0.9440, \mathrm{P} 25 \mathrm{M}$ vs. F: $P=0.3570, \mathrm{P} 30 \mathrm{M}$ vs. F: $P=$ 0.0042) (Fig. 2C), suggesting possible higher freezing levels for females compared with males at the P30 time point.

While studies have implicated developmental changes in the hippocampus in infantile forgetting (Akers et al. 2014; Guskjolen et al. 2018; Travaglia et al. 2018), much less is known about the contribution of other brain areas involved in remote memory, such as the prefrontal cortex (Takehara et al. 2003; Frankland et al. 2004a; Frankland and Bontempi 2005; Vetere et al. 2011; Wheeler et al. 2013; Kitamura et al. 2017; DeNardo et al. 2019; Grella et al. 2020; Pan et al. 2020; Sathiyakumar et al. 2020), in this process. In adult rodents, recruitment of neuronal activity in the prelimbic cortex (PL) has been shown to occur following remote, but not recent, fear memory retrieval (Frankland et al. 2004a; Wheeler et al. 2013; DeNardo et al. 2019; Grella et al. 2020). We therefore looked at neuronal activation in the PL following the 1-d or 30-d contextual fear retrieval in P15 and P30 mice (Fig. 3A). P15 animals, which are unable to successfully retrieve a 30-d old contextual fear memory, showed equivalent recruitment of c-Fos positive cells in the PL following 1-d and 30-d memory retrieval (unpaired $t$-test: $t_{(10)}=$ 0.33, $P=0.7434$ ) (Fig. 3B). In contrast, P30 animals showed a significant increase in the percentage of c-Fos positive cells in the PL at the 30-d compared with the 1-d retrieval test (unpaired $t$-test: $t_{(10)}=2.86$, $P=0.0170$ ) (Fig. 3C). This effect was not driven by age-dependent differences in baseline c-fos expression (Supplemental Fig. 2A) or by context exposure (Supplemental Fig. 2B). These data show that successful 30-d contextual fear memory retrieval at $\mathrm{P} 30$ is accompanied by the increased activation of PL neurons at the remote time point, an effect that is absent in P15 animals.

\section{Discussion}

fear at either P15, P21, P25, or P30 then tested for memory retrieval 1 d or 30 d later. Training consisted of one (P15) or six (P21, P25, and P30) tone-shock pairings (10-sec 2000-Hz, 80-dB tone; 0.6-mA, 1-sec footshock). (A) Schematic of auditory fear conditioning. (B) Percent freezing at the $1-\mathrm{d}$ retrieval test across age groups. All age groups exhibited robust freezing behavior. P15, $n=9$ ( 5 males, 4 females); P21, $n=11$ (4 males, 7 females); P25, $n=7$ ( 3 males, 4 females); P30, $n=10$ ( 5 males, 5 females). (C) Percent freezing at the 30-d retrieval test across age groups. P15 and P21 groups exhibited minimal freezing behavior, while P25 and P30 groups displayed significantly higher freezing. P15, $n=5$ (2 males, 3 females); P21, $n=9$ (5 males, 4 females); P25, $n=10$ (5 males, 5 females); P30, $n=11$ $\left(5\right.$ males, 6 females). All data represent mean \pm SEM. $\left(^{*}\right) P<0.05$. Female (orange) and male (purple) data points are identified, but no sex differences were found across experiments, except for an age $x$ sex interaction effect at P30 in the P30-d retrieval test (see the Results for details).
We refined the time line for the developmental emergence of persistent (30-d) memory for contextual fear in C57BL/ $6 \mathrm{~J}$ mice, identifying P21-P25 as the interval for when the ability to generate persistent contextual fear memory emerges. We next investigated the 
A

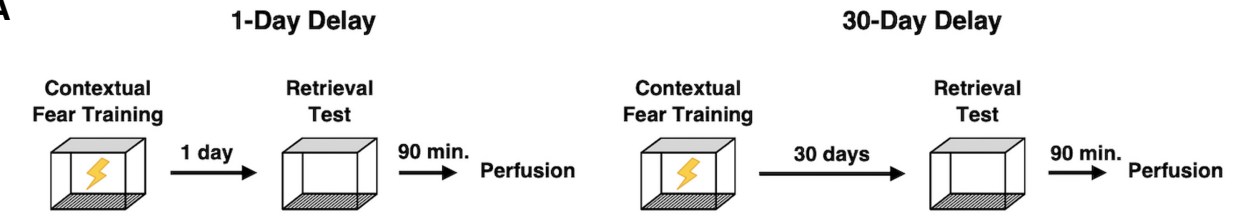

B
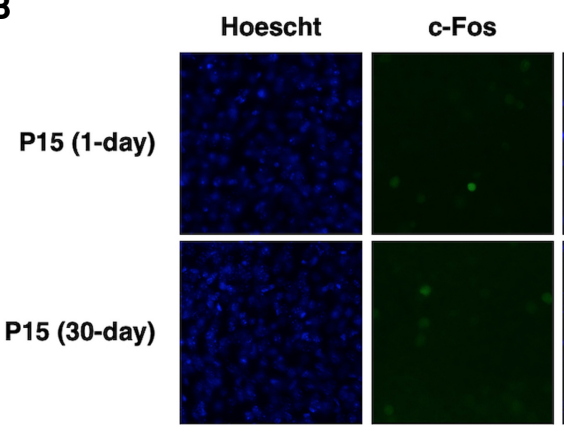

Overlay

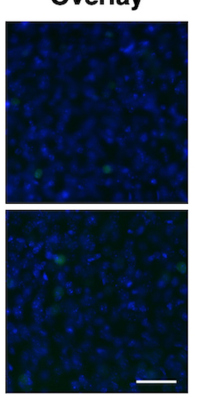

P15

C

$$
\text { Hoescht }
$$
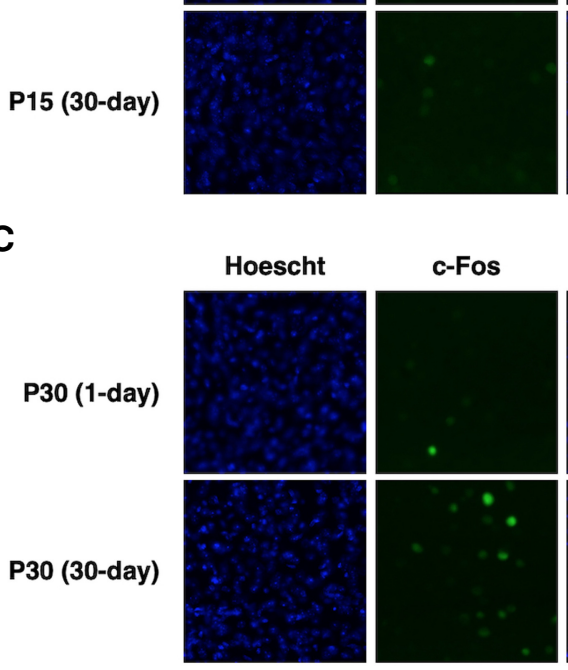

c-Fos

Overlay
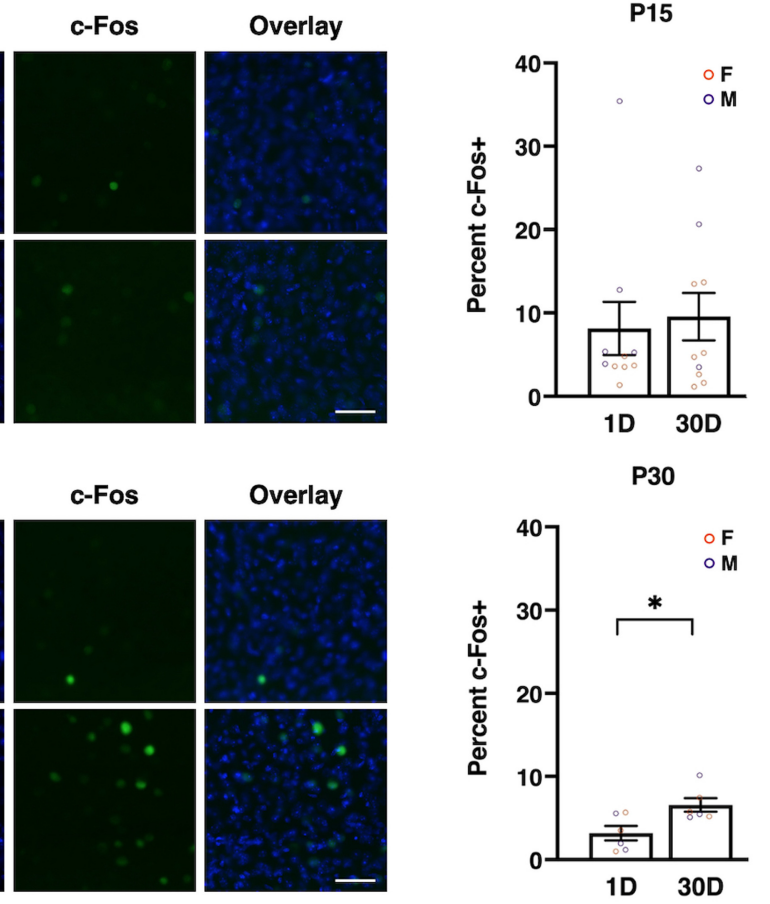

Figure 3. Developmental recruitment of prelimbic cortex following 1-d and 30-d contextual fear retrieval. C57BL/6) mice were trained in contextual fear at either P15 or P30, then re-exposed to the training context $1 \mathrm{~d}$ or $30 \mathrm{~d}$ later. Ninety-minutes after the retrieval test, mice were perfused for immunohistochemistry against c-Fos. (A) Schematic of contextual fear conditioning and perfusion. (B) Percent c-Fos-positive cells over the total number of Hoechst-stained cells at either 1-d or 30-d retrieval tests in animals trained at P15. No differences were found between retrieval time points. 1-d, $n=10$ (5 males, 5 females); 30-d, $n=10$ (3 males, 7 females). (C) Percent c-Fos positive cells over the total number of cells at either the 1-d or 30-d retrieval test in animals trained at P30. c-Fos expression was significantly higher at the 30-d retrieval test compared with the 1-d test. $1 \mathrm{~d}, n=6$ (3 males, 3 females); $30 \mathrm{~d}, n=6$ (3 males, 3 females). All data represent mean \pm SEM. $\left(^{*}\right) P<0.05$. Female (orange) and male (purple) data points are identified. Scale bar, $50 \mu \mathrm{m}$.

ontogeny of persistent memory for auditory fear, a commonly used behavioral task with partially overlapping features and underlying neural circuitry (Phillips and LeDoux 1992; Maren 2001; Sotres-Bayon et al. 2012; Maren et al. 2013; Herry and Johansen 2014). We found that persistent (30-d) auditory fear memory emerges within a similar time line to that of contextual fear, between P21 and P25. Importantly, late weaning did not rescue the persistent memory deficit seen in P21 animals, suggesting that the effects of same-day weaning on the auditory or contextual fear cohorts were not responsible for their respective absence of persistent memory. These data suggest synchronous emergence of the ability to generate persistent memories for both context- and tone-fear associations in mice. Additionally, we investigated whether the developmental onset of fear memory persistence was accompanied by neural signatures of remote memory recall. We found that P30 animals displayed higher PL activation at the 30-d memory retrieval test compared with the 1-d memory retrieval test, an effect that was absent in P15 mice. These results show that remote (30-d) context re-exposure is unable to trigger fear memory retrieval or PL recruitment in animals trained at P15. These data identify the precise ontogeny of persistent memory for contextual and auditory fear in mice and provide novel in- sight into the neural correlates of remote memory retrieval across development.

Studies examining the ontogeny of context conditioning in mice are relatively few (Revillo et al. 2015). The onset of persistent ( $\geq 28$-d) memory for contextual fear in mice has been reported between P15/P17 and P30 (Akers et al. 2012; Guskjolen et al. 2018), a finding that is replicated in our present study. This also suggests a convergence between C57/129 (Akers et al. 2012; Guskjolen et al. 2018) and C57BL/6 mouse strains in the ontogeny of persistent memory for contextual fear. In rats, persistent contextual fear memory has been found to be absent at P30 and earlier ages (Campbell and Campbell 1962; Beane et al. 2002; Weber et al. 2006), with one study showing its emergence at P38 (Campbell and Campbell 1962). Given that the delay intervals between fear training and retrieval tests vary considerably between these rat studies ( 7 to $42 \mathrm{~d}$ ) and ours ( $30 \mathrm{~d}$ ), and that the requirement for the hippocampus in contextual fear retrieval may differ between these delays (Kim and Fanselow 1992; Anagnostaras et al. 1999), these data may not be directly comparable. Therefore, based on the available studies, we cannot conclusively say that mice display an earlier emergence of persistent memory for contextual fear compared with rats. Furthermore, it is important to 
note that postnatal age in each species may differ in terms of brain and behavioral development (Clancy et al. 2001). We only found one study looking at remote auditory fear memory during development in rodents, which showed that P23 rats were unable to retain auditory fear memories for $7 \mathrm{~d}$ ( $\mathrm{Li}$ et al. 2012a), consistent with our time line. Although we cannot exclude the possibility that the onset of persistent memory for contextual and auditory fear may diverge within the P21-P25 time window, these data point to a largely consistent ontogenetic time line for persistent memory for contextual and auditory fear in mice and for auditory fear for both mice and rats. We found no evidence of sex differences in the age of onset for persistent contextual or auditory fear conditioning. To our knowledge, sex differences in fear learning during early life have only been found in fear extinction (Park et al. 2017), and had not been examined within the context of the developmental onset of memory persistence in either rats or mice.

The onset of 1-d memory for both contextual and auditory fear in rats has been observed as early as P15-P18 (Mckinzie and Spear 1995; Pugh and Rudy 1996; Beane et al. 2002; Brasser and Spear 2004; Revillo et al. 2015). We found robust 1-d freezing in mice to both context and tone from P15, the earliest age tested, consistent with previous reports (Akers et al. 2012). While several groups vary the number of auditory tone-shock pairings delivered to P15-17 rodents to equate their freezing to that of older animals (Gogolla et al. 2009; Kim et al. 2009; Kim and Richardson 2007, 2008), we and others (Akers et al. 2012; Jablonski et al. 2012; Bath et al. 2016; Guskjolen et al. 2018) found this adjustment was not necessary in contextual fear. These observations point to developmental differences in fear memory processing that are specific to stimulus-association type, even if they do not extend to memory persistence. Finally, we acknowledge that through optimizing training for remote retrieval across ages within each fear category, differences in experimental design limit our ability to directly compare behavioral output for contextual and auditory fear.

Several studies point to hippocampal maturation as a major factor in guiding the onset of fear memory persistence, likely by enabling the long-term retrieval of infant memories. Furthermore, our data show that a correlate of remote memory retrieval, activation of the prefrontal cortex (Takehara et al. 2003; Frankland et al. 2004a; Frankland and Bontempi 2005; Vetere et al. 2011; Wheeler et al. 2013; Kitamura et al. 2017; DeNardo et al. 2019; Grella et al. 2020; Pan et al. 2020; Sathiyakumar et al. 2020), is absent for infant memories. Interestingly, Guskjolen et al. (2018) found that adult retrieval of P17 memories through optogenetic manipulation of hippocampal neuronal ensembles reinstated patterns of neuronal activity in brain regions such as the entorhinal cortex, but not PL. Future work is needed to determine precisely how early life changes in the hippocampus (Akers et al. 2014; Callaghan et al. 2014; Travaglia et al. 2016b, 2018), and/or the prefrontal cortex ( $\mathrm{Li}$ et al. 2012a,b) may render memories more accessible for retrieval at long delays. Additionally, this group showed that persistent (30-d) spatial memory for the Morris water maze (MWM) is already present in mice at P20 (Guskjolen et al. 2017), considerably earlier than the onset of persistent memory for contextual fear. Combined with our data, this suggests asynchrony in the ontogeny of memory persistence within hippocampus-dependent memory types. While research has shown a role for PL in the remote retrieval of auditory fear memories (Do-Monte et al. 2015), direct assessment of PL engagement in remote auditory fear in early life is necessary to further link the onset of behavior and neural correlates between these two types of fear memory. Overall, these data consolidate a precise time line for the emergence of memory persistence for context- and toneshock associations in mice, a necessary step toward understanding the neural basis of aversive memory encoding and retrieval across the life span.

\section{Materials and Methods}

\section{Animals}

Male and female C57BL/6J mice (Jackson Laboratory) were bred at the University of Toronto Scarborough and kept on a $12 \mathrm{~h}$ lightdark cycle (lights on at 07:00 h) with access to food and water ad libitum. Date of birth was designated postnatal day $(\mathrm{P}) 0$, with litter sizes ranging from two to nine pups. All litters were randomly divided and evenly distributed (including by sex) between ages (e.g., P15, P21, P25, P28, and P30) and experimental groups (1-d and 30-d retrieval tests), with a minimum of two ages per litter to minimize litter effects. If more than one same-sex littermate was used in the same age group, littermate data were averaged toward a singular data point to minimize the effects of litter on data variability. For all experiments, animals were only tested at a single delay (either 1 or $30 \mathrm{~d}$ ), to exclude possible effects of a previous retrieval session on subsequent memory. Animals were kept with the dam until weaning at P21 and subsequently separated by sex and litter into housing of two to five animals per cage on a lightdark cycle with food and water delivered ad libitum. To minimize the effects of weaning on memory consolidation, training and weaning were separated by an interval of up to $6 \mathrm{~h}$. Preliminary data from our laboratory did not find an effect of weaning shortly after or $6 \mathrm{~h}$ after training on remote memory retrieval. Behavioral procedures were performed during the early light phase between 07:00 and 12:00 $\mathrm{h}$. All animal procedures were approved by the Animal Care Committee at the University of Toronto.

\section{Behavioral testing}

\section{Contextual fear conditioning}

All contextual fear conditioning procedures were conducted in a soundproof stainless steel conditioning chamber $(30 \mathrm{~cm} \times 24 \mathrm{~cm}$ $\times 21 \mathrm{~cm}$, Med Associates) containing a removable stainless-steel shock grid floor (context A). Shock grid bars (3.2 mm diameter) were spaced $8.1 \mathrm{~mm}$ apart. The grid floor was located above a stainless-steel drop pan, which was cleaned with $70 \%$ ethanol between sessions. The front and top of the chamber were made of clear acrylic, and the two sides and back were made of modular aluminum. Mice were fear trained at either P15, P21, P25, P28, or P30. Training consisted of a $120 \mathrm{sec}$ acclimation period to the conditioning chamber, followed by five footshocks $(0.5 \mathrm{~mA}, 2 \mathrm{sec})$ delivered at 60-sec intervals (Guskjolen et al. 2018). Mice were removed from the chamber $60 \mathrm{sec}$ after the last footshock and transported back into their home cage. Retrieval was conducted either $1 \mathrm{~d}$ or $30 \mathrm{~d}$ after the initial fear training. During contextual fear retrieval, mice were placed back into the original training chamber (context A) for a duration of $5 \mathrm{~min}$, and freezing behavior was recorded and quantified by an automated motion-sensitive software with a minimum freezing duration of $1 \mathrm{sec}$ for the 5-min duration of the tests (VideoFreeze, Med Associates). For the context-only group (Supplemental Fig. 2), animals underwent the same procedure as described above for contextual fear conditioning, but in the absence of footshocks during training.

\section{Immediate shock}

Two age groups, P25 and P28, were used for the immediate shock (IMS) control experiment. Within each age group, mice were split between either a contextual fear conditioning or an IMS group. Mice in the contextual fear conditioning group underwent the same training procedures described above. Mice in the IMS group were placed in context $A$ and received one footshock $(0.5 \mathrm{~mA}$, $2 \mathrm{sec}$ ) immediately upon entering the chamber. Mice remained in the chamber for an additional $60 \mathrm{sec}$, and were then removed and transported back into their home cage (Frankland et al. 2004b; Arruda-Carvalho and Clem 2014). Retrieval was conducted $30 \mathrm{~d}$ later. During retrieval, mice were placed back into context A 
for a duration of $5 \mathrm{~min}$, and freezing behavior was recorded and quantified by an automated motion-sensitive software as described for contextual fear (VideoFreeze, Med Associates).

\section{Auditory fear conditioning}

All auditory fear conditioning procedures were conducted in a soundproof stainless steel conditioning chamber $(30 \mathrm{~cm} \times 24 \mathrm{~cm}$ $\times 21 \mathrm{~cm}$, Med Associates). Auditory fear training took place in context A, as previously described. Mice were fear trained at either P15, $\mathrm{P} 21$, P25, or P30. Following a 120-sec acclimation period to the conditioning chamber, P21, P25, and P30 mice received six presentations of a 10-sec tone $(2000 \mathrm{~Hz}, 80 \mathrm{~dB})$, which coterminated with a footshock $(0.6 \mathrm{~mA}, 1 \mathrm{sec})$, spaced by 60 -sec intervals (adapted from Gogolla et al. 2009). Mice trained at P15 received only one tone-shock pairing, as data from our laboratory established that this equated their 1-d retrieval freezing levels to that of older animals. All mice were removed from the chamber $60 \mathrm{sec}$ after the last tone-shock presentation and transported back into their home cage. Memory retrieval took place either $1 \mathrm{~d}$ or $30 \mathrm{~d}$ after training in context B. In context B, a white plastic floor covered the shock grids and a white plastic sheet covered the side and back walls in a semicircle. For memory retrieval, following a 120 -sec acclimation period, mice were presented with five 10 -sec tones $(2000 \mathrm{~Hz}, 8 \mathrm{~dB})$ at 60 -sec intervals (adapted from Gogolla et al. 2009). Mice were removed from the chamber $60 \mathrm{sec}$ after the last tone presentation and were transported back into their home cage. Freezing behavior was recorded and quantified by an automated motion-sensitive software with a minimum freezing duration of $1 \mathrm{sec}$ (VideoFreeze, Med Associates). Freezing was measured during baseline (first $120 \mathrm{sec}$ ), as well as the five 10-sec tone presentations and averaged across five tones. Due to a COVID19-related laboratory shutdown, five animals had to be tested 4-5 d earlier in the 30-d retrieval test for auditory fear, as it was the last day in which the laboratory was open. Two of these animals were in the P21 group (tested $26 \mathrm{~d}$ after training, average percent freezing across tones: $15 \%$ and $15.6 \%$ ) and three in the P25 group (tested $25 \mathrm{~d}$ after training, average percent freezing across tones: $0 \%, 46.5 \%$, and $51.4 \%$ ). Since this slightly shorter interval (1) remains conceptually consistent with a measurement of persistent memory, (2) is similar or very close to delays commonly used by other groups for remote memory testing (e.g., 28-d delay [Maren et al. 1996; Wang et al. 2009; Goshen et al. 2011; Kwon et al. 2012; Do-Monte et al. 2015; Poulos et al. 2016; Todd et al. 2016] and P21-d delay [Khalaf and Gräff 2019; Grella et al. 2020]), and (3) evidence suggests freezing levels do not significantly change between remote retrieval intervals (Kim and Fanselow 1992; Maren et al. 1996; Do-Monte et al. 2015;), we opted to include them in this data set.

Dedicated cohorts of mice were used in each fear task according to the retention interval.

\section{Delayed weaning}

To examine whether same-day weaning influenced the absence of persistent memory in the P21 group, we trained animals in auditory and contextual fear (as described above) at P21, then weaned animals $4 \mathrm{~d}$ later at P25. To prevent double litters, male breeders were removed from the breeding cage once the female was pregnant, or in the rare case where pregnancy was not visually evident, immediately after the birth of a new litter. All animals within one litter were either trained in auditory or contextual fear (i.e., dedicated cohorts), and to minimize litter effects, each experimental condition was comprised of at least two litters.

\section{Immunohistochemistry}

Ninety-minutes following the end of the contextual fear retrieval tests for the animals represented in Figure 1, mice were anesthetized and perfused transcardially with $0.01 \mathrm{M}$ phosphate-buffered saline (PBS), followed by 4\% paraformaldehyde (PFA). The brains were extracted and postfixed in 4\% PFA overnight. Coronal sections $(50 \mu \mathrm{m})$ were cut using a vibratome (Leica VT1000s). The pri- mary antibody used was rabbit polyclonal anti-c-Fos (1:5000; Synaptic Systems 226003$)$ in TNB $(0.5 \%$ Roche blocking reagent in $1 \times$ Tris/NaCl buffer). All sections were treated with $1 \%$ hydrogen peroxide. Sections were incubated overnight at $4^{\circ} \mathrm{C}$ with the primary antibody and then for $60 \mathrm{~min}$ at room temperature with donkey antirabbit secondary antibody conjugated with horseradish peroxidase (HRP; 1:500; Jackson ImmunoResearch 711-036-152) in TNB. Signals were amplified using tyramide signal amplification conjugated with NHS-fluorescein. All sections were treated with Hoechst nuclear dye (1:1000; Thermo Fisher H1399) for $10 \mathrm{~min}$ at room temperature. Sections were mounted on slides with Permafluor antifade medium (Fisher Scientific TA-030-FM).

\section{Imaging and quantification}

Images were acquired using an upright epifluorescent microscope (Nikon Eclipse Ni-U). For cell counts in PL, we used one-fifth systematic section sampling fractions covering the entire anteroposterior extent of the PL (Franklin and Paxinos 2007). All cell counts were performed using ImageJ/Fiji (National Institutes of Health). Total Hoechst-stained cell counts were obtained using the "Analyze Particles" tool and optimized to a 3500-65,536 threshold level, 0-infinity square millimeter size, and 0.00-1.00 circularity, as these parameters produced the most accurate total cell counts when compared with our manual counts. c-Fos-positive cell counts were obtained manually using the "Cell Counter" plug-in. Due to variability in total Hoechst-stained cells across groups (one-way ANOVA, $F_{(3,28)}=10.98, P<0.0001$; Tukey's post-hoc test: P15 $1 \mathrm{~d}$ vs. P15 30 d: $P=0.0280, P 151 \mathrm{~d}$ vs. P30 $1 \mathrm{~d}: P=0.0245$, P15 $1 \mathrm{~d}$ vs. P30 30 d: $P=0.6873, P 1530$ d vs P30 1 d: $P<0.0001, P 1530 \mathrm{~d}$ vs. P30 30 d: $P=0.4638$, P30 1 d vs. P30 $30 \mathrm{~d}: P=0.0047)$, we analyzed c-Fos expression as a percentage of the total number of cells sampled, calculated by dividing the number of c-Fos+ cells by the total number of Hoechst-stained cells (adapted from Grella et al. 2020).

\section{Statistical analysis}

Data are presented as mean \pm SEM. All statistical analyses were obtained using Graphpad Prism software. To compare freezing behavior of animals across age groups within the 1-d or the 30-d groups, one-way ANOVA tests were performed, followed by Tukey's posthoc multiple comparisons tests. For the immediate shock experiment, an unpaired two-tailed $t$-test was conducted for each age group of interest. To determine any differences in percent c-Fos at 1 -d versus $30-\mathrm{d}$ retrieval time points, an unpaired two-tailed $t$-test was performed for each age group of interest. Potential sex differences were first assessed using a two-way ANOVA. Since we found no significant effects of sex on 1-d or 30-d memory retrieval for contextual or auditory fear, data were collapsed across these variables for subsequent analyses.

\section{Acknowledgments}

We thank Dr. Helen Chasiotis for technical assistance with ordering and breeding animals and with immunohistochemistry, and Hanista Premachandran for assistance with behavior. This work was supported by the Natural Science and Engineering Research Council of Canada (NSERC; RGPIN-2017-06344), as well as an NSERC CGS-D (CGSD3 534884-2019) to A.C.-S.

\section{References}

Akers KG, Arruda-Carvalho M, Josselyn SA, Frankland PW. 2012. Ontogeny of contextual fear memory formation, specificity, and persistence in mice. Learn Mem 19: 598-604. doi:10.1101/lm.027581.112

Akers KG, Martinez-Canabal A, Restivo L, Yiu AP, De Cristofaro A, Hsiang HL, Wheeler AL, Guskjolen A, Niibori Y, Shoji H, et al. 2014. Hippocampal neurogenesis regulates forgetting during adulthood and infancy. Science 344: 598-602. doi:10.1126/science.1248903

Alberini CM, Travaglia A. 2017. Infantile amnesia: a critical period of learning to learn and remember. J Neurosci 37: 5783-5795. doi:10.1523/ JNEUROSCI.0324-17.2017 
Albo Z, Gräff J. 2018. The mysteries of remote memory. Philos Trans R Soc B Biol Sci 373: 20170029. doi:10.1098/rstb.2017.0029

Anagnostaras SG, Maren S, Fanselow MS. 1999. Temporally graded retrograde amnesia of contextual fear after hippocampal damage in rats: within-subjects examination. J Neurosci 19: 1106-1114. doi:10.1523/ JNEUROSCI.19-03-01106.1999

Anagnostaras SG, Gale GD, Fanselow MS. 2001. Hippocampus and contextual fear conditioning: recent controversies and advances. Hippocampus 11: 8-17. doi:10.1002/1098-1063(2001)11:1<8:: AID-HIPO1015>3.0.CO;2-7

Arruda-Carvalho M, Clem RL. 2014. Pathway-selective adjustment of prefrontal-amygdala transmission during fear encoding. J Neurosci 34: 15601-15609. doi:10.1523/JNEUROSCI.2664-14.2014

Bath KG, Manzano-Nieves G, Goodwill H. 2016. Early life stress accelerates behavioral and neural maturation of the hippocampus in male mice. Horm Behav 82: 64-71. doi:10.1016/j.yhbeh.2016.04.010

Beane ML, Cole MA, Spencer RL, Rudy JW. 2002. Neonatal handling enhances contextual fear conditioning and alters corticosterone stress responses in young rats. Horm Behav 41: 33-40. doi:10.1006/hbeh.2001 .1725

Bergstrom HC. 2016. The neurocircuitry of remote cued fear memory. Neurosci Biobehav Rev 71: 409-417. doi:10.1016/j.neubiorev.2016.09 .028

Brasser SM, Spear NE. 2004. Contextual conditioning in infants, but not older animals, is facilitated by CS conditioning. Neurobiol Learn Mem 81: 46-59. doi:10.1016/S1074-7427(03)00068-6

Brown JS, Kalish HI, Farber IE. 1951. Conditioned fear as revealed by magnitude of startle response to an auditory stimulus. J Exp Psychol 41: 317-328. doi:10.1037/h0060166

Callaghan BL, Li S, Richardson R. 2014. The elusive engram: what can infantile amnesia tell us about memory? Trends Neurosci 37: 47-53. doi:10.1016/j.tins.2013.10.007

Campbell BA, Campbell EH. 1962. Retention and extinction of learned fear in infant and adult rats. J Comp Physiol Psychol 55: 1-8. doi:10.1037/ h0049182

Campbell BA, Jaynes J. 1966. Reinstatement. Psychol Rev 73: 478-480. doi:10.1037/h0023679

Campbell BA, Spear NE. 1972. Ontogeny of memory. Psychol Rev 79: 215236. doi:10.1037/h0032690

Clancy B, Darlington RB, Finlay BL. 2001. Translating developmental time across mammalian species. Neuroscience 105: 7-17. doi:10.1016/ S0306-4522(01)00171-3

Cleveland ES, Reese E. 2008. Children remember early childhood: long-term recall across the offset of childhood amnesia. Appl Cogn Psychol 22: 127142. doi:10.1002/acp.1359

Cope ZA, Powell SB, Young JW. 2016. Modeling neurodevelopmental cognitive deficits in tasks with cross-species translational validity. Genes Brain Behav 15: 27-44. doi:10.1111/gbb.12268

Davis JM, Rovee-Collier CK. 1983. Alleviated forgetting of a learned contingency in 8-week-old infants. Dev Psychol 19: 353-365. doi:10 $.1037 / 0012-1649.19 .3 .353$

Davis N, Gross J, Hayne H. 2008. Defining the boundary of childhood amnesia. Memory 16: 465-467. doi:10.1080/09658210802077082

DeNardo LA, Liu CD, Allen WE, Adams EL, Friedmann D, Fu L, Guenthner CJ, Tessier-Lavigne M, Luo L. 2019. Temporal evolution of cortical ensembles promoting remote memory retrieval. Nat Neurosci 22: 460-469. doi:10.1038/s41593-018-0318-7

Do-Monte FH, Quinõnes-Laracuente K, Quirk GJ. 2015. A temporal shift in the circuits mediating retrieval of fear memory. Nature 519: 460-463. doi:10.1038/nature14030

Fanselow MS. 1990. Factors governing one-trial contextual conditioning. Anim Learn Behav 18: 264-270. doi:10.3758/BF03205285

Frankland PW, Bontempi B. 2005. The organization of recent and remote memories. Nat Rev Neurosci 6: 119-130. doi:10.1038/nrn1607

Frankland PW, Bontempi B, Talton LE, Kaczmarek L, Silva AJ. 2004a. The involvement of the anterior cingulate cortex in remote contextual fear memory. Science 304: 881-883. doi:10.1126/science.1094804

Frankland PW, Josselyn SA, Anagnostaras SG, Kogan JH, Takahashi E, Silva AJ. 2004b. Consolidation of CS and US representations in associative fear conditioning. Hippocampus 14: 557-569. doi:10.1002/ hipo. 10208

Franklin KBJ, Paxinos G. 2007. The mouse brain in stereotaxic coordinates, 3rd ed. Elsevier Academic Press, San Diego.

Gogolla N, Caroni P, Lüthi A, Herry C. 2009. Perineuronal nets protect fear memories from erasure. Science 325: 1258-1261. doi:10.1126/science .1174146

Goshen I, Brodsky M, Prakash R, Wallace J, Gradinaru V, Ramakrishnan C, Deisseroth K. 2011. Dynamics of retrieval strategies for remote memories. Cell 147: 678-689. doi:10.1016/j.cell.2011.09.033

Grella SL, Fortin AH, McKissick O, Leblanc H, Ramirez S. 2020. Odor modulates the temporal dynamics of fear memory consolidation. Learn Mem 27: 150-163. doi:10.1101/lm.050690.119
Guskjolen A, Josselyn SA, Frankland PW. 2017. Age-dependent changes in spatial memory retention and flexibility in mice. Neurobiol Learn Mem 143: 59-66. doi:10.1016/j.nlm.2016.12.006

Guskjolen A, Kenney JW, De La Parra J, Yeung BA, Josselyn SA, Frankland PW. 2018. Recovery of 'lost' infant memories in mice. Curr Biol 28: 2283-2290. doi:10.1016/j.cub.2018.05.059

Haroutunian V, Riccio DC. 1977. Effect of arousal conditions during reinstatement treatment upon learned fear in young rats. Dev Psychobiol 10: $25-32$. doi: $10.1002 /$ dev.420100105

Heim C, Nemeroff CB. 2001. The role of childhood trauma in the neurobiology of mood and anxiety disorders: preclinical and clinical studies. Biol Psychiatry 49: 1023-1039. doi:10.1016/S0006-3223(01) 01157-X

Herry C, Johansen JP. 2014. Encoding of fear learning and memory in distributed neuronal circuits. Nat Neurosci 17: 1644-1654. doi:10.1038/ nn.3869

Howes M, Siegel M, Brown F. 1993. Early childhood memories: accuracy and affect. Cognition 47: 95-119. doi:10.1016/0010-0277(93)90001-C

Jablonski SA, Schiffino FL, Stanton ME. 2012. Role of age, post-training consolidation, and conjunctive associations in the ontogeny of the context preexposure facilitation effect. Dev Psychobiol 54: 714-722. doi:10.1002/dev.20621

Josselyn SA, Frankland PW. 2012. Infantile amnesia: a neurogenic hypothesis. Learn Mem 19: 423-433. doi:10.1101/lm.021311.110

Kaffman A, Krystal JH. 2012. New frontiers in animal research of psychiatric illness. Methods Mol Biol 829: 3-30. doi:10.1007/978-1-61779-458-2_1

Khalaf O, Gräff J. 2019. Reactivation of recall-induced neurons in the infralimbic cortex and the basolateral amygdala after remote fear memory attenuation. Front Mol Neurosci 12: 70. doi:10.3389/fnmol .2019 .00070

Kihlstrom JF, Harackiewicz JM. 1982. The earliest recollection: a new survey. J Pers 50: 134-148. doi:10.1111/j.1467-6494.1982.tb01019.x

Kim JJ, Fanselow MS. 1992. Modality-specific retrograde amnesia of fear. Science 256: 675-677. doi:10.1126/science. 1585183

Kim JH, Richardson R. 2007. A developmental dissociation in reinstatement of an extinguished fear response in rats. Neurobiol Learn Mem 88: 48-57. doi:10.1016/j.nlm.2007.03.004

Kim JH, Richardson R. 2008. The effect of temporary amygdala inactivation on extinction and reextinction of fear in the developing rat: unlearning as a potential mechanism for extinction early in development. J Neurosci 28: 1282-1290. doi:10.1523/JNEUROSCI.4736-07.2008

Kim JH, McNally GP, Richardson R. 2006. Recovery of fear memories in rats: role of $\gamma$-amino butyric acid (GABA) in infantile amnesia. Behav Neurosci 120: $40-48$. doi:10.1037/0735-7044.120.1.40

Kim JH, Hamlin AS, Richardson R. 2009. Fear extinction across development: the involvement of the medial prefrontal cortex as assessed by temporary inactivation and immunohistochemistry. $J$ Neurosci 29: 10802-10808. doi:10.1523/JNEUROSCI.0596-09.2009

Kitamura T, Ogawa SK, Roy DS, Okuyama T, Morrissey MK, Smith LM, Redondo RL, Tonegawa S. 2017. Engrams and circuits crucial for systems consolidation of a memory. Science 356: 73-78. doi:10.1126/science .aam6808

Kwon JT, Jhang J, Kim HS, Lee S, Han J. 2012. Brain region-specific activity patterns after recent or remote memory retrieval of auditory conditioned fear. Learn Mem 19: 487-494. doi:10.1101/lm.025502.112

Ledoux JE. 2000. Emotion circuits in the brain. Аnnu Rev Neurosci 23: 155184. doi:10.1146/annurev.neuro.23.1.155

LeDoux JE, Cicchetti P, Xagoraris A, Romanski LM. 1990. The lateral amygdaloid nucleus: sensory interface of the amygdala in fear conditioning. J Neurosci 4: 1062-1069. doi:10.1523/JNEUROSCI .10-04-01062.1990

Li S, Kim JH, Richardson R. 2012a. Updating memories: changing the involvement of the prelimbic cortex in the expression of an infant fear memory. Neuroscience 222: 316-325. doi:10.1016/j.neuroscience.2012 .06 .038

Li S, Kim JH, Richardson R. 2012b. Differential involvement of the medial prefrontal cortex in the expression of learned fear across development. Behav Neurosci 126: 217-225. doi:10.1037/a0027151

Maren S. 2001. Neurobiology of pavlovian fear conditioning. Annu Rev Neurosci 24: 897-931. doi:10.1146/annurev.neuro.24.1.897

Maren S, Aharonov G, Fanselow MS. 1996. Retrograde abolition of conditional fear after excitotoxic lesions in the basolateral amygdala of rats: absence of a temporal gradient. Behav Neurosci 4: 718-726. doi:10 $.1037 / 0735-7044.110 .4 .718$

Maren S, Phan KL, Liberzon I. 2013. The contextual brain: implications for fear conditioning, extinction and psychopathology. Nat Rev Neurosci 14: 417-428. doi:10.1038/nrn3492

Mckinzie DL, Spear NE. 1995. Ontogenetic differences in conditioning to context and CS as a function of context saliency and CS-US interval. Anim Learn Behav 23: 304-313. doi:10.3758/BF03198927 
Pan S, Mayoral SR, Choi HS, Chan JR, Kheirbek MA. 2020. Preservation of a remote fear memory requires new myelin formation. Nat Neurosci 23: 487-499. doi:10.1038/s41593-019-0582-1

Park CHJ, Ganella DE, Kim JH. 2017. Juveile female rats, but not male rats, show renewal, reinstatement, and spontaneous recovery following extinction of conditioned fear. Learn Mem 24: 630-636. doi:10.1101/lm 045831.117

Phillips RG, LeDoux JE. 1992. Differential contribution of amygdala and hippocampus to cued and contextual fear conditioning. Behav Neurosci 106: 274-285. doi:10.1037/0735-7044.106.2.274

Poulos AM, Mehta N, Lu B, Amir D, Livingston B, Santarelli A, Zhuravka I, Fanselow MS. 2016. Conditioning- and time-dependent increases in context fear and generalization. Learn Mem 23: 379-385. doi:10.1101/ $\operatorname{lm} .041400 .115$

Pugh CR, Rudy JW. 1996. A developmental analysis of contextual fear conditioning. Dev Psychobiol 29: 87-100. doi:10.1002/(SICI)1098-2302 (199603)29:2<87::AID-DEV1>3.0.CO;2-H

Ramsaran AI, Schlichting ML, Frankland PW. 2018. The ontogeny of memory persistence and specificity. Dev Cogn Neurosci 36: 100591. doi:10.1016/j.dcn.2018.09.002

Revillo DA, Cotella E, Paglini MG, Arias C. 2015. Contextual learning and context effects during infancy: 30 years of controversial research revisited. Physiol Behav 148: 6-21. doi:10.1016/j.physbeh.2015.02.012

Richardson R, Riccio DC, McKenney M. 1988. Stimulus attributes of reactivated memory: alleviation of ontogenetic forgetting in rats is context specific. Dev Psychobiol 21: 135-143. doi:10.1002/dev .420210203

Rubin DC. 2000. The distribution of early childhood memories. Memory 8: 265-269. doi:10.1080/096582100406810

Rubin DC, Schulkind MD. 1997. The distribution of autobiographical memories across the lifespan. Mem Cognit 25: 859-866. doi:10.3758/ BF03211330

Rudy JW, Morledge P. 1994. Ontogeny of contextual fear conditioning in rats: implications for consolidation, infantile amnesia, and hippocampal system function. Behav Neurosci 108: 227-234. doi:10 .1037/0735-7044.108.2.227

Sathiyakumar S, Skromne Carrasco S, Saad L, Richards BA. 2020. Systems consolidation impairs behavioral flexibility. Learn Mem 27: 201-208. doi:10.1101/lm.051243.119

Scarf D, Gross J, Colombo M, Hayne H. 2013. To have and to hold: episodic memory in 3- and 4-year-old children. Dev Psychobiol 55: 125-132. doi:10.1002/dev.21004

Schroeder A, Notaras M, Du X, Hill RA. 2018. On the developmental timing of stress: delineating sex-specific effects of stress across development on adult behavior. Brain Sci 8: 121. doi:10.3390/brainsci8070121

Sotres-Bayon F, Sierra-Mercado D, Pardilla-Delgado E, Quirk GJ. 2012. Gating of fear in prelimbic cortex by hippocampal and amygdala inputs. Neuron 76: 804-812. doi:10.1016/j.neuron.2012.09.028

Spear LP. 2000. The adolescent brain and age-related behavioral manifestations. Neurosci Biobehav Rev 24: 417-463. doi:10.1016/ S0149-7634(00)00014-2
Spear NE, Parsons PJ. 2014. Analysis of a reactivation treatment: ontogenetic determinants of alleviated forgetting. In Processes of animal memory (PLE: Memory), 1st ed. (ed. Medin DL, et al.), pp. 135-165. Psychology Press, Hove, East Sussex, UK.

Squire LR. 2004. Memory systems of the brain: a brief history and current perspective. Neurobiol Learn Mem 82: 171-177. doi:10.1016/j.nlm.2004 .06 .005

Syed SA, Nemeroff CB. 2017. Early life stress, mood, and anxiety disorders. Chronic Stress 1: 2470547017694461. doi:10.1177/2470547017694461

Takehara K, Kawahara S, Kirino Y. 2003. Time-dependent reorganization of the brain components underlying memory retention in trace eyeblink conditioning. J Neurosci 23: 9897-9905. doi:10.1523/JNEUROSCI .23-30-09897.2003

Todd TP, Mehlman ML, Keene CS, DeAngeli NE, Bucci DJ. 2016. Retrosplenial cortex is required for the retrieval of remote memory for auditory cues. Learn Mem 23: 278-288. doi:10.1101/lm.041822.116

Travaglia A, Bisaz R, Cruz E, Alberini CM. 2016a. Developmental changes in plasticity, synaptic, glia and connectivity protein levels in rat dorsal hippocampus. Neurobiol Learn Mem 135: 125-138. doi:10.1016/j.nlm .2016.08.005

Travaglia A, Bisaz R, Sweet ES, Blitzer RD, Alberini CM. 2016b. Infantile amnesia reflects a developmental critical period for hippocampal learning. Nat Neurosci 19: 1225-1233. doi:10.1038/nn.4348

Travaglia A, Steinmetz AB, Miranda JM, Alberini CM. 2018. Mechanisms of critical period in the hippocampus underlie object location learning and memory in infant rats. Learn Mem 25: 176-182. doi:10.1101/lm.046946 .117

Tustin K, Hayne H. 2010. Defining the boundary: age-related changes in childhood amnesia. Dev Psychol 46: 1049-1061. doi:10.1037/a0020105

Vetere G, Restivo L, Cole CJ, Ross PJ, Ammassari-Teule M, Josselyn SA, Frankland PW. 2011. Spine growth in the anterior cingulate cortex is necessary for the consolidation of contextual fear memory. Proc Natl Acad Sci 108: 8456-8460. doi:10.1073/pnas.1016275108

Waldfogel S. 1948. The frequency and affective character of childhood memories. Psychol Monogr Gen Appl 62: i-39. doi:10.1037/h0093581

Wang S, Teixeira CM, Wheeler AL, Frankland PW. 2009. The precision of remote context memories does not require the hippocampus. Nat Neurosci 12: 253-255. doi:10.1038/nn.2263

Weber M, McNally GP, Richardson R. 2006. Opioid receptors regulate retrieval of infant fear memories: effects of naloxone on infantile amnesia. Behav Neurosci 120: 702-709. doi:10.1037/0735-7044.120.3.702

Wheeler AL, Teixeira CM, Wang AH, Xiong X, Kovacevic N, Lerch JP, McIntosh AR, Parkinson J, Frankland PW. 2013. Identification of a functional connectome for long-term fear memory in mice. PLoS Comput Biol 9: e1002853. doi:10.1371/journal.pcbi.1002853

White SH, Pillemer DB. 1979. Childhood amnesia and the development of a socially accessible memory system. In Functional disorders of memory. Experimental psychology series (ed. Kihlstrom JF, Evans FJ), Lawrence Earlbaum Associates, Hillsdale, New Jersey.

Received July 9, 2021; accepted in revised form July 30, 2021. 


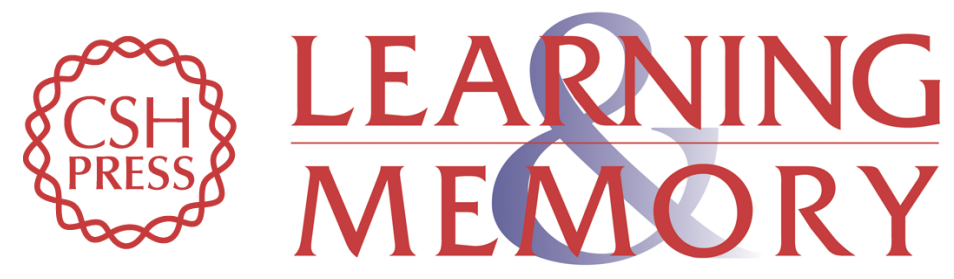

\section{Developmental emergence of persistent memory for contextual and auditory fear in mice}

Rojina Samifanni, Mudi Zhao, Arely Cruz-Sanchez, et al.

Learn. Mem. 2021, 28:

Access the most recent version at doi:10.1101//m.053471.121

\section{Supplemental http://learnmem.cshlp.org/content/suppl/2021/09/29/28.11.414.DC1 Material}

References This article cites 85 articles, 21 of which can be accessed free at: http://learnmem.cshlp.org/content/28/11/414.full.html\#ref-list-1

Creative This article is distributed exclusively by Cold Spring Harbor Laboratory Press for the Commons first 12 months after the full-issue publication date (see

License http://learnmem.cshlp.org/site/misc/terms.xhtml). After 12 months, it is available under a Creative Commons License (Attribution-NonCommercial 4.0 International), as described at http://creativecommons.org/licenses/by-nc/4.0/.

Email Alerting Receive free email alerts when new articles cite this article - sign up in the box at the Service top right corner of the article or click here. 